\title{
Reversal of curvature magnitude in response to physical methods: a I5-year followup in an adult female diagnosed with moderately severe scoliosis at age eleven years
} William J Brooks*1,2, Elizabeth A Krupinski ${ }^{3}$ and Martha C Hawes ${ }^{4}$

\author{
Email: William J Brooks* - wjbdo@wjbrooksdo.com \\ * Corresponding author \\ from 4th International Conference on Conservative Management of Spinal Deformities \\ Boston, MA, USA. 13-16 May 2007 \\ Published: 12 October 2007 \\ Scoliosis 2007, 2(Suppl I):P2 doi:I0.II86/I748-7|6I-2-SI-P2
}

Address: ${ }^{1}$ Restorative Care Foundation, Kansas City, MO 64152, USA, ${ }^{2}$ Department of Osteopathic Principles and Practice, College of Osteopathic Medicine, Nova Southeastern University, Ft. Lauderdale, FL 33328, USA, ${ }^{3}$ Department of Radiology, Arizona Health Sciences Center, University of Arizona, Tucson AZ 85721, USA and 4Department of Plant Sciences, University of Arizona, Tucson, AZ 85721, USA

This abstract is available from: http://www.scoliosisjournal.com/content/2/SI/P2

(C) 2007 Brooks et al; licensee BioMed Central Ltd.

\section{Objective}

To document improvement in curvature magnitude in moderately severe pediatric onset scoliosis, in an adult, without surgery.

\section{Study design}

An adult case report was monitored from age thirty-eight years through fifty-four years of age. Repeated measures analysis of variance (ANOVA) was used to evaluate change in magnitude of Cobb angle, based on values obtained by three independent readers, using full spine radiographs taken at four-year intervals.

\section{Methods}

A multimodal physical therapy approach included deep tissue massage and osteopathic manipulation, in combination with a daily home exercise program.

\section{Results}

Stable, progressive improvement in Cobb angle occurred over a fifteen-year period in response to physical methods. The improved curvature occurred in correlation with progressive improvement of chest wall morphology and excursion.

\section{Conclusion}

The forty percent (thoracic curve) and fifty percent (lumbar curve) reduction in curvature magnitude compares favorably with results from surgical intervention [1].

\section{References}

I. Bradford DS, Kay BKB, Hu SS: Adult scoliosis: surgical indications, operative management, complications and outcomes. Spine 1999, 24:2617-2629. 